\title{
Prevalence of Female Sexual Dysfunction among Women with Pelvic Organ Prolapse Diagnosed by Pisq-12 and Related Factors in Hung Vuong Hospital, Vietnam
}

\author{
Huynh Nguyen Khanh Trang1,2, Pham Hung Cuong3, Hoang Thi Diem Tuyet ${ }^{2}$ \\ ${ }^{1}$ Pham Ngoc Thach University of Medicine, Ho Chi Minh City, Vietnam \\ ${ }^{2}$ Hung Vuong Hospital, Ho Chi Minh City, Vietnam \\ ${ }^{3}$ University of Medical and Pharmacy, Ho Chi Minh City, Vietnam \\ Email: tranghnk08@gmail.com
}

How to cite this paper: Trang, H.N.K., Cuong, P.H. and Tuyet, H.T.D. (2019) Prevalence of Female Sexual Dysfunction among Women with Pelvic Organ Prolapse Diagnosed by Pisq-12 and Related Factors in Hung Vuong Hospital, Vietnam. Open Journal of Obstetrics and Gynecology, 9, 1005-1018.

https://doi.org/10.4236/ojog.2019.97098

Received: May 20, 2019

Accepted: July 19, 2019

Published: July 22, 2019

Copyright $\odot 2019$ by author(s) and Scientific Research Publishing Inc. This work is licensed under the Creative Commons Attribution International License (CC BY 4.0).

http://creativecommons.org/licenses/by/4.0/

\section{(c) (i) Open Access}

\begin{abstract}
Pelvic organ prolapsed is a common problem today, and it has been gradually increasing because of the longevity of women. Pelvic organ prolapse can result in negative psychological feelings that affect on women's sexual activity. Methods: There is a cross-sectional study on sexual dysfunction in 296 women with pelvic organ prolapse grade II and III followed up at gynecological-pelvic floor unit of Hung Vuong hospital from 09/2017 to 06/2018. Results: The prevalence of female sexual dysfunction in PISQ-12 was 76.4\% and 95\% CI [71.6 - 81.2]. The rate of female sexual dysfunction in turn is: 1) Behavioral-Emotional: 93.6\% 95\% CI [90.8 - 96.4]. 2) Physiology: 62.2\% CI 95\% [56.7 - 67.7]. 3) Relationship to partner: 89.5\% 95\% CI [86.0 - 93.0]. Factor related to sexual dysfunction in women with pelvic organs $(p<0.05)$ is general sexual dysfunction: 1) Age group: women over age 55 increased generally the risk of sexual dysfunction, OR $=5.89,95 \%$ CI [1.38 - 25.20]. 2) Diabetes mellitus increased the risk of sexual dysfunction with OR $=5.03,95 \%$ CI $[1.42$ - 17.82]. 3) Patients with previous abortions reduced the risk of sexual dysfunction with OR $=0.4995 \%$ CI [0.27 - 0.90]. Conclusion: Research on quality of life in pelvic organ prolapse should be considered more in the future.
\end{abstract}

\section{Keywords}

Pelvic Organ Prolapse, Sexual Dysfunction, Pelvic Organ Prolapse Quantification System (POP-Q), Pelvic Organ Prolapse/Urinary Incontinence Sexual Function Questionnaire-12 (PISQ-12) 


\section{Introduction}

Pelvic organ prolapse (POP) is a common problem nowadays, gradually increasing in the current economic and social life because of the increasing age of women. Most women are affected, and about $11 \%$ have to undergo surgery for treatment of POP. The awareness of women's sexual activity directly affects their own health and also affects their treatment.

Human sexual activity is instinctive and influenced by many biological, psychological, social and cultural factors and relationships with partners. When sexual function is disordered, the first negative effect will manifest in the physiological mind (such as sadness, depression, anger), and mental manifestations (such as restlessness, suspicion, depression, concerned). Sexual dysfunction also negatively affects the family atmosphere, productivity, as well as other relationships and above all affects the treatment process, treatment effectiveness, and as a result difficulties in treatment. Many studies have noted that sexual dysfunction affects overall woman's quality of life, so it is important to consider related factors to help them improve their quality of life. To assess this problem, a questionnaire on quality of life can be used. These questionnaires have been used in many studies on different subjects such as postoperative patients with POP, cardiac surgery, cancer pathology [1].

Hung Vuong Hospital is a specialized obstetric and gynecological hospital in Ho Chi Minh city, in the south of Vietnam. We have more than 200 doctors and 900 patient beds. The number of hysterectomy due to POP is about 100 cases per year among nearly 600 cases of hysterectomy.

POP can create negative feelings about psychology, affecting women's sexual activity. Researching this problem in the world is not much and gives many conflicting results about the relationship between pelvic organism and sexual dysfunction. The limitation in research may be due to the use of questionnaires about non-specific, non-specific sexual functions.

In recent years, pelvic experts have agreed to use the PISQ-12 questionnaire (Prolapse/Urinary Incontinence Sexual Questionnaire) to identify sexual dysfunction in proven pelvic patients. The Pelvic Organ Prolapse/Urinary Incontinence Sexual Questionnaire-12 (PISQ-12) was developed from the data of 99 of 182 women surveyed to create the long form (PISQ-31) [2]. An additional 46 patients were recruited for further validation. All subsets regression analysis identified 12 items likely to predict PISQ-31 scores. Short form scores underwent correlation analysis with long form, Incontinence Impact Questionnaire-7 (IIQ-7), Sexual History Form-12 (SHF-12) and Symptom Questionnaire (SQ) scores. Test-retest reliability was checked with a subset of 20 patients. All subsets regression analysis with $R>0.92$ identified 12 items that predicted PISQ-31 scores. Short form scores were highly correlated with long-form scores $(R=0.75-0.95)$. Correlations of the PISQ-12 with SHF-12 ( $R=-0.66$ and -0.68$)$ and IIQ-7 ( $R=$ -0.38 and -0.54$)$ scores were similar to correlation of the PISQ-31 with these other measures. Reliability was moderate to high, with weighted $j$ values from 
0.56 to 0.93 . PISQ-12 scores were lower in patients with low sexual function as measured on the SHF-12 $(p<0.001)$, and lower in women with depression as measured on the SQ $(p<0.001)$. The PISQ-12 is a validated and reliable short form that evaluates sexual function in women with urinary incontinence and/or pelvic organ prolapse and predicts PISQ-31 scores. It is able to distinguish women with poor sexual function as measured on the SHF-12. Is valuable, concise, useful clinically [3] [4].

With the research question "What is the rate of sexual dysfunction in patients with POP at Hung Vuong hospital?", We conducted research on this issue.

\section{Goals of the Study}

1) Determine the prevalence of sexual dysfunction in patients with POP at Hung Vuong hospital, Ho Chi Minh city, Vietnam.

2) Identify the sexual disorder related factors in patients with POP such as age, ethnicity, smoking, pre-obstetric, birth, weight at the highest birth, body mass index, internal diseases, pre-surgery gynecology, menopause.

\section{Subjects and Methods}

\subsection{Cross-Sectional Study}

Sampling: Patients examined in gynecological and pelvic units at Hung Vuong Hospital-Ho Chi Minh City, Vietnam met the criteria for sampling and agreed to participate in the study.

Sample size is calculated according to the formula

$$
N=Z_{(1-\alpha)}^{2} p(1-p) / d^{2}
$$

In which: $n$ : size of research sample.

Conducting a research study of more than 30 patients with pelvic organs at Hung Vuong Hospital, the results of the questionnaire had 28/30 people answered the whole question, reaching $93.3 \%$. 93.3\% said that the questionnaire was easy to understand and did not need to be edited. $6.7 \%$ said that the questionnaire had some difficult questions to answer. The average time to complete 12 sentences is 5 minutes, of which the shortest is 3 minutes, the longest is $10 \mathrm{mi}$ nutes. The rate of sexual dysfunction in navigational research is $80.6 \%$. So the minimum sample size needs to be 241 objects.

Select continuous samples at gynecological and pelvic clinics of Hung Vuong hospital from September, 2017 to June, 2018. The study selected 296 subjects.

Sampling criteria: Women who suffered from pelvic prolapse (level II or higher according to POP-Q), agreed to participate in the study, had sexual activity within 6 months.

Exclusion criteria Patients who do not agree to participate in the study. $\mathrm{Pa}$ tients have no sexual partners, or no sexual activity within 6 months. Women have pregnant. Patients cannot participate in interviews such as illiteracy, dumbness or deafness. 
Pelvic prolapse: Pelvic Organ Prolapse Quantification System (POP-Q, Appendix 1), the points in the POP-Q examination, except for the vaginal length, will be determined by the most rising point when performing the Valsava test, or cough test. Pelvic organs prolapse are determined when POP-Q is at grade II or higher.

Preparing the questionnaire PISQ-12 (Appendix 2) based on the International Committee's translation process of Questionnaire Evaluation Quality of Life, we perform the following steps in order to build the PISQ question set-12 Vietnamese, which applies to research.

\subsection{Steps to Proceed}

Step 1: Screening subjects: Researchers will conduct interviews and examine patients at the gynecological and pelvic clinic of Hung Vuong hospital from the time they visit.

Step 2: Invite subjects to participate in the study: These patients, after being well advised about the purpose, the way to proceed, the benefits and disadvantages of the study will sign a consensus to participate in the study when they agree to participate, time for each object about 10 minutes. Only those who agree to participate in the study will begin conducting interviews.

Step 3: Interview and collect information: face-to-face interviews. All research subjects will be interviewed according to the questionnaire in two parts: 1) Questionnaire on research variables. 2) Sex function evaluation questionnaire including: Questionnaire PISQ-12. Examination, classifying POP-Q accordingto pelvicorgans prolapse.

Data in the study will be coded, imported, managed, and analyzed based on SPSS 20 software.

\section{Results}

\subsection{Comment}

The sample had an average age of $48.2 \pm 9.0$, the youngest age was 30 , the highest age was 66. Women aged 50 - 59 accounted for the highest proportion of $41.2 \%$. Ethnic groups are predominantly Vietnam (87.8\%), China ethnic group accounts for $3.0 \%$ and about $1 / 10$ are other ethnic groups. The majority of research samples with overweight BMI (60.8\%), obesity accounted for at least $5.4 \%$, and about one fifth of heavy labor. Secondary education accounted for $48.3 \%$, education level vấn level 1 accounted for $39.9 \%$, about $7.1 \%$ level 3 and $4.7 \%$ university, postgraduate. Current medical conditions in the study sample include $14.2 \%$ of patients with a history of diabetes, $28 \%$ of patients with hypertension and $7.1 \%$ of patients with smoking. The majority of patients with pelvic leprosy level II $87.5 \%$ and level III are $12.5 \%$. The number of vaginal births: most patients $\geq 3$ times vaginal birth $49.7 \%$, none of them have never had vaginal birth before. Number of caesarean births: about $4 / 5$ patients have never had a caesarean, and $7.1 \%$ of patients have had a Caesarean birth at least 2 times. The 
largest birth weight of the majority from 3000 - $3499 \mathrm{~g}$ accounted for $68.2 \%$, about 1 in 10 cases with the highest birth weight of the baby $\geq 4000 \mathrm{~g}$, and the highest rate of birth born $<3000 \mathrm{~g}$ accounted for $3.7 \%$. Gynecological precursors: About $45.6 \%$ of patients have menopause, $5.7 \%$ of patients have undergone hysterectomy. About $43.9 \%$ of patients had had at least one abortion before.

About $12.2 \%$ of cases have used hormone replacement therapy during menopause (Table 1).

Prevalence of sexual disorder among POP patients, evaluated by PISQ-12 is $76.4 \%, 95 \%$ CI [71.6 - 81.2].

\subsection{Comment}

One subject may have many sexual disorders at the same time, so the total number of women with sexual disorders is more than the total number of 296 women in the study. The pattern of emotional behavior disorder has the highest rate of 93.6\% 95\% CI [90.8 - 96.4]; Next in descending order is the disorder associated with partners $89.5 \% 95 \%$ CI [86.0 - 93.0], and the lowest rate of physiological disorder 62.2\% CI $95 \%$ [56.7 - 67.7] (Table 2).

\subsection{Comment}

After introducing 8 factors related to general sexual dysfunction into multivariate regression models to control confounding factors, the results have a real correlation between the following factors with disorder General sexual function, $p<0.05$. Women over 55 years of age increased the risk of general sexual dysfunction with OR $=5.8995 \%$ CI $[1.38$ - 25.20]. Diabetes status increases the risk of general sexual dysfunction with $\mathrm{OR}=5.0395 \%$ CI [1.42 - 17.82]. Patients with a history of abortion reduce the risk of sexual dysfunction with $\mathrm{OR}=0.49$ $95 \%$ CI $[0.27-0.90]$.

\section{Discussion}

Sexual issues of people began to be interested in around the XVIII century, when some authors learned about the psychological aspect of sexual behavior. Many researchers have tried to understand and identify "normal" sexual behavior through the use of a number of different survey methods. In 1997, urologists were the first to use the term "female sexual disorder" to refer to the pathophysiology of female genital organs.

Female sexual disorders are repeated problems in sexual response, affecting psychology and relationships with partners, which is a complex, not well known and influential disease of all ages [5]. Sexual dysfunction is common in women suffering from pelvic prolapse. It is often caused by many factors including psychosocial factors, urinary tract atrophy, advanced age, male sexual dysfunction [6].

Research design: with the aim of finding the rate of female sexual dysfunction, at the same time identifying factors related to sexual disorders in patients with 
Table 1. Characteristics of study paticipants $(n=296)$.

\begin{tabular}{|c|c|c|}
\hline Characteristics & Number (n) & Percentage (\%) \\
\hline \multicolumn{3}{|l|}{ Ages } \\
\hline 30 - 39 years old & 55 & 18.6 \\
\hline 40 - 49 years old & 99 & 33.4 \\
\hline 50 - 59 years old & 122 & 41.2 \\
\hline$\geq 60$ years old & 20 & 6.8 \\
\hline \multicolumn{3}{|l|}{ Work level } \\
\hline Light & 231 & 78.0 \\
\hline Heavy & 65 & 22.0 \\
\hline \multicolumn{3}{|l|}{ Education } \\
\hline Primary & 118 & 39.9 \\
\hline Secondary & 143 & 48.3 \\
\hline High school & 21 & 7.1 \\
\hline$\geq$ Colledge & 14 & 4.7 \\
\hline \multicolumn{3}{|l|}{ BMI } \\
\hline Normal & 100 & 33.8 \\
\hline Overweigth & 180 & 60.8 \\
\hline Obesity & 16 & 5.4 \\
\hline \multicolumn{3}{|l|}{ Diabetes } \\
\hline Yes & 42 & 14.2 \\
\hline No & 254 & 85.8 \\
\hline \multicolumn{3}{|l|}{ Hypertension } \\
\hline Yes & 83 & 28.0 \\
\hline No & 213 & 72.0 \\
\hline \multicolumn{3}{|l|}{ Smoking } \\
\hline Yes & 21 & 7.1 \\
\hline No & 275 & 92.9 \\
\hline \multicolumn{3}{|l|}{ Hysterectomy } \\
\hline Yes & 17 & 5.7 \\
\hline No & 279 & 94.3 \\
\hline \multicolumn{3}{|l|}{ Abortion } \\
\hline No & 130 & 43.9 \\
\hline Yes & 166 & 56.1 \\
\hline \multicolumn{3}{|c|}{ Heaviest children birth weigth } \\
\hline$<3000$ gr & 11 & 3.8 \\
\hline $3000 \leq 3500$ gr & 202 & $68 ., 2$ \\
\hline $3500 \leq 4000 \mathrm{gr}$ & 58 & 19.6 \\
\hline$\geq 4000 \mathrm{gr}$ & 25 & 8.4 \\
\hline
\end{tabular}




\section{Continued}

\begin{tabular}{ccc} 
Menopause & & \\
Yes & 135 & 45.6 \\
No & 161 & 54.4 \\
HRT* & & \\
Yes & 36 & 12.2 \\
No & 260 & 87.8 \\
Vaginal delivery & & \\
1 time & 39 & 13.2 \\
2 times & 110 & 37.2 \\
$\geq 3$ times & 147 & 49.6 \\
Cesarean section & & 14.2 \\
1 time & 42 & 7.1 \\
$\geq 2$ times & 21 & 78.7 \\
0 time & 233 & \\
POP grade & & 87.5 \\
II & 259 & 12.5 \\
III & 37 & \\
\hline
\end{tabular}

${ }^{\star} \mathrm{HRT}=$ hormon replacement therapy.

Table 2. Types of sexual disorder among POP patients $(n=296)$.

\begin{tabular}{cccc}
\hline Types & Number of case & Percentage & Confident interval 95\% \\
\hline Behavioral-emotional disorder & 277 & 93.6 & $90.8-96.4$ \\
Physiological problems & 184 & 62.2 & $56.7-67.7$ \\
Related mates disorder & 265 & 89.5 & $86.0-93.0$ \\
General sexual disorder & 226 & 76.4 & $71.6-81.2$
\end{tabular}

pelvic organ prolapse (Table 2). So we chose a cross-sectional study design that is consistent with the research goal, which can be done in a hospital with a short study period.

Subjects of the study: study population was sampled in pelvic floor patients who visited the gynecological clinic, Hung Vuong hospital. These patients were diagnosed with pelvic organ prolapse at Hung Vuong hospital according to POP-Q and never had any previous treatment or intervention. Our data collection table is carefully prepared, complete, for research purposes. After study interview, these patients continued to be monitored and treated according to the hospital regimen.

How to collect and analyze data: the sample size in our study is 296 cases (Table 1). We choose samples in a convenient sequential manner until sufficient quantities are available. Combined with the gynecological examination, we completed the data collection table. Specific, encrypted data collection tables so that the information obtained is objective, confidential and accurate. 
The study period was 10 months, in which 1 month conducted a trial study of the PISQ-12 questionnaire after translating into Vietnamese, determining the value and reliability of the questionnaire, and 6 months of implementation.

Our study showed that the rate of general sexual dysfunction of women with pelvic spleen was $76.4 \%$ with an average PISQ-12 index of $30.30 \pm 5.82$, a total average score on a scale of PISQ-12 is quite low at 30.30/48 points (maximum score of PISQ-12 scale). The general form of sexual dysfunction is a collection of 12 questions of PISQ-12, which summarizes the relationship between factors to give an average score, thereby comparing and determining sexual dysfunction. The general form of sexual disorder is also a collection of the meanings of the three small morphologies above, describing the most important factors to assess the sexual life of a specific subject, the siblings. Behavioral-emotional disturbances, or physiological or merely disordered disorders due to partners, just one of the three factors on the disorder can lead to other forms of confusion. disorder and reduce the quality of the sexual life of a woman with pelvic organs.

In multivariate regression analysis (Table 3 ), a real correlation was found between the age group and sexual dysfunction $(p<0.05)$, as follows: Women over 55 years of age had an increased risk of confusion. general sexual dysfunction with $\mathrm{OR}=5.8995 \% \mathrm{CI}[1.38-25.20]$. Patients 55 years and older increase the risk of physiological disorders OR $=5.85 ; 95 \%$ CI [2.31 - 14.78]. The association between age groups and sexual dysfunction according to PISQ-12 on pelvic subjects is also determined by several studies worldwide [7] [8]. According to research by Sylvia M. Botros (2006), there is a correlation between the age group above 50 and the low PISQ-12 index (difference in average score -5.4 with $p=$ 0.019) [9].

The older the patient, the more likely he is to suffer from diseases, the organs in the body and the structures that support the pelvic area weaken, and the physiological problems also change in the downward direction. The advanced age is the factor of pelvic organ, the higher the age, the more likely it is that the pelvic organ will become more severe. According to the POSST study [10], 100\% of the

Table 3. Multi-variate regression analysis of factors relating to sexual disorder among POP patients.

\begin{tabular}{ccccc}
\hline Variables & OR & OR adjusted & $95 \% \mathrm{CI}$ & $P^{* *}$ \\
\hline Age $\geq 55$ & 8.87 & 5.89 & $1.38-25.20$ & 0.017 \\
BMI Overweigth & 0.55 & 0.53 & $0.27-1.03$ & 0.059 \\
Hypertension, yes & 3.30 & 1.34 & $0.55-3.29$ & 0.524 \\
Diabetes, yes & 4.66 & 5.03 & $1.42-17.82$ & 0.012 \\
Menopause, yes & 4.61 & 1.58 & $0.53-4.76$ & 0.414 \\
HRT, yes & 2.07 & 2.17 & $0.53-8.96$ & 0.283 \\
Abortion, yes & 0.67 & 0.49 & $0.27-0.90$ & 0.022 \\
POP grade III & 3.96 & 2.23 & $0.59-8.42$ & 0.236
\end{tabular}

$p^{\star *}$ Multi-variate regression. 
risk of pelvic prolapse increases with each decade. Women aged 20 - 59 years, the proportion of pelvic organs doubled every decade. The increase is due to a decrease in Estrogen. According to Hendrix et al., OR $1.16(1.0-1.3)$ in women 60 - 69 years, OR $1.36(1.2$ - 1.6) in women 70 - 79 years of age compared to 50 59 year-old women with uterine prolapse [4]. In a cross-sectional study of 21,449 Italian women, the incidence of pelvic proliferation increased with age also correlated, between women under 51 years of age compared to 52 - 55 years OR 1.3 (1.1 - 1.5), and compared to over 56 OR 1.7 (1.5 - 2.0) [11] [12].

The relationship between chronic diseases such as diabetes and sexual dysfunction is determined by several studies worldwide [7]. In our study, precursor abortion was a factor in reducing sexual dysfunction with $\mathrm{OR}=0.49$ and $p<$ 0.05 . This may be due to an increase in abortion rates, a reduction in birth rates, especially vaginal births, thereby reducing the incidence of pelvic spleen as well as pelvic floor prolapse, which may reduce dysfunction sex.

Limitation of the study:

Cross-sectional design should be limited in deducing the causal factors of female sexual disorders. In the future, prospective, longitudinal design studies are needed to investigate causal factors related to female sexual disorders, across different female subjects.

The questionnaire of PISQ-12 surveyed sexual life in the past 6 months, suitable for the group of pelvic subjects, who had low frequency of sexual intercourse, however, it was difficult to avoid recall due to time is too long.

Some related factors have not been surveyed: sexual harassment/sexual abuse history, sexual preference. This is a complicated issue, very difficult to conduct research, because most people want to avoid, want to not remember, or do not want to mention.

\section{Conclusions}

Through 296 cases of pelvic organ prolapse grade II and III at Hung Vuong hospital, we draw some conclusions as follows:

1) The prevalence of female sexual dysfunction in pelvic organ prolapse according to PISQ-12 is $76.4 \%$ 95\% CI [71.6 - 81.2]. The proportion of female sexual disorders patterns are: 1) Behavior-emotions: 93.6\% 95\% CI [90.8 - 96.4]. 2) Physiology: 62.2\% 95\% CI [56.7 - 67.7]. 3) Relation to partners: $89.5 \% 95 \% \mathrm{CI}$ [86.0 - 93.0].

2) Factor related to sexual disorders in women with pelvic women $(p<0.05)$ is general sexual disorder: 1) Age group: women over 55 years of age increased the risk of general sexual dysfunction with OR $=5.8995 \%$ CI [1.38 - 25.20]. 2) Diabetes status increases the risk of general sexual dysfunction with OR $=5.0395 \%$ CI [1.42 - 17.82]. 3) Patients with a history of abortion reduce the risk of general sexual dysfunction with $\mathrm{OR}=0.4995 \% \mathrm{CI}[0.27-0.90]$.

\section{Conflicts of Interest}

The authors declare no conflicts of interest regarding the publication of this paper. 


\section{References}

[1] Rivalta, M., Sighinolfi, M.C. and Micali, S. (2010) Sexual Function and Quality of Life in Women with Urinary Incontinence Treated by a Complete Pelvic Floor Rehabilitation Program. The Journal of Sexual Medicine, 7, 1200-1208. https://doi.org/10.1111/j.1743-6109.2009.01676.x

[2] Rogers, R.G., Coates, K.W., Kammerer-Doak, D., Khalsa, S. and Qualls, C. (2003) A Short form of the Pelvic Organ Prolapse/Urinary Incontinence Sexual Questionnaire (PISQ-12). International Urogynecology Journal and Pelvic Floor Dysfunction International Urogynecological Association, 14, 164-168. https://doi.org/10.1037/t31466-000

[3] Kammerer, D.D. (2009) Assessment of Sexual Function in Women with Pelvic Floor Dysfunction. IUGA Female Sexual Dysfunction Foundtable, 20, 45-50. https://doi.org/10.1007/s00192-009-0832-y

[4] Brent, P.A., et al. (2011) Validation of Web-Based Administration of the Pelvic Organ Prolapse/Urinary Incontinence Sexual Function Questionnaire (PISQ-12). International Urogynecology Journal, 22, 357-361. https://doi.org/10.1007/s00192-010-1297-8

[5] McAnulty, R.D. and Burnette, M.M (2006) Sexual Function and Dysfunction. Sex and Sexuality, 14-32.

[6] Aschkenazi, S.O. and Goldberg, R.P. (2009) Female Sexual Function and the Pelvic Floor. Expert Review of Obstetrics \& Gynecology, 4, 165-178.

https://doi.org/10.1586/17474108.4.2.165

[7] Simbar, S.N.M. and Tehrani, F.R. (2015) Factors of the Sexual Function in Menopause. Taiwanese Journal of Obstetrics \& Gynecology, 55, 480-487. https://doi.org/10.1016/j.tjog.2016.06.001

[8] Yang, S.H., Yang, J.M., Wang, K.H. and Huang, W.C. (2008) Biologic Correlates of Sexual Function in Women with Stress Urinary Incontinence. The Journal of Sexual Medicine, 5, 2871-2879. https://doi.org/10.1111/j.1743-6109.2008.00985.x

[9] Botros, S.M. and Abramov, Y. (2006) Effect of Parity on Sexual Function. American College of Obstetricians and Gynecologists, 107, 765-770. https://doi.org/10.1097/01.AOG.0000207677.03235.76

[10] Hendrix, S.L., Clark, A., Nygaard, et al. (2002) Pelvic Prolapse Organ in Women's Health. American Journal of Obstetrics \& Gynecology, 186, 1160-1166. https://doi.org/10.1067/mob.2002.123819

[11] Francesco, A., et al. (2009) The Influence of BMI, Smoking, and Vaginal Age Erosions after Synthetic Mesh Repair of Pelvic Organ Prolapses. A Multicenter Study. Acta Obstetricia et Gynecologica Scandinavica, 88, 772-780. https://doi.org/10.1080/00016340903002840

[12] Progetto Menopausa Italia Study Group (2000) Risk Factor for Genital Prolapse in Non-Hysterectomized Women around Menopausa. European Journal of Obstetrics \& Gynecology, 89, 501-506. 


\section{Appendix 1}

Examination for pelvic organ prolapse was done in dorsal lithotomy position (position in which the patient is on their back with the hips and knees flexed and thighs apart) in OPD. Inspection of the vulva and perineum was done first.

After inspection, the labia were separated and any prolapse was noted. Prolapse was graded by using the POP Q system. Plane of hymen is defined as zero. Points above hymen were given negative number and points below hymen positive number (Figure A1). All the measurements were made in $\mathrm{cm}( \pm 0.5$ $\mathrm{cm})$.

\section{POP Q System Has Following Points of Measurement}

- Aa: It is a fixed landmark. It defines a point that lies in the midline of the anterior vaginal wall and is $3 \mathrm{~cm}$ proximal to the external urethral meatus. It corresponds to the proximal location of the urethrovesical crease. In relation to the hymen, this point ranges from -3 (i.e. normal support) to +3 (i.e. maximum prolapse).

- Ba: It is a variable point and refers to the most distal position of any part of the remaining upper anterior vaginal wall. It is $-3 \mathrm{~cm}$ in the absence of prolapse. Points range is -3 (in the absence of prolapse) to $+\operatorname{tvl}(-3$ to +8$)$. In the absence of prolapse $\mathrm{Aa}$ and $\mathrm{Ba}$ are almost same point i.e. $(-3)$.

- Ap: It defines a point that lies in the midline of the posterior vaginal wall and is $3 \mathrm{~cm}$ proximal to the hymen. This point's range is -3 (i.e. normal support) to +3 (maximum prolapse of point Ap).

- Bp: it is also a variable point, most distal point of the remaining upper posterior vaginal wall. Point range is -3 (in the absence of prolapse) to + tvl $(-3$ to +8$)$

- In the absence of prolapse Ap and Bp are almost the same point (-3).

- Total vaginal length (tvl): greatest depth of the vagina in centimeters measurement is taken without straining (normal range is $8-12 \mathrm{~cm}$ ).

- Genital hiatus (gh): middle of external urethral meatus to the posterior midline of hymen (range $2-4 \mathrm{~cm}$ ).

- Perineal body (pb): posterior margin of genital hiatus to midanal opening

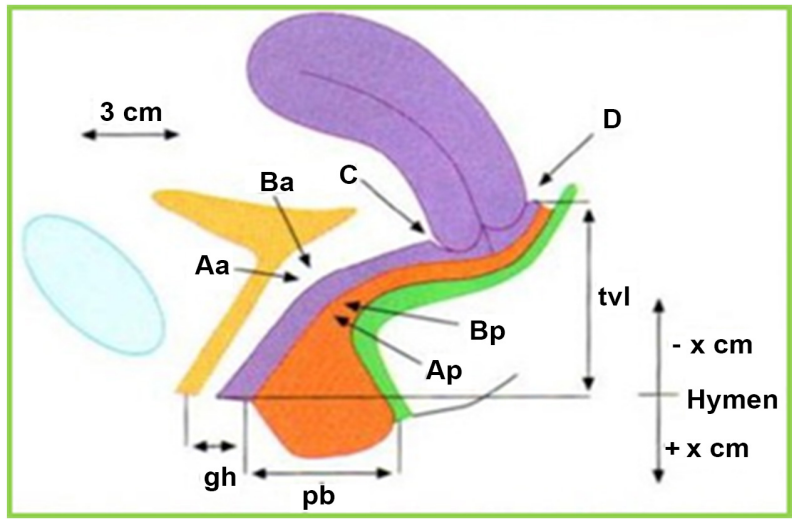

Figure A1. Illustration of points of POP Q. 
(approx. $3 \mathrm{~cm}$ ).

- D (douglas): level of uterosacral ligament attachment to the posterior cervix (no cervix $=$ no $d$ point, range -8 to -10 ).

- C (cervix or vaginal cuff): most distal edge of the cervix or leading edge of the vaginal cuff.

Ask the patient to be on the examination according to the gynecological examination.

$\mathrm{Gh}, \mathrm{Pb}$ (Figure A2) and Tvl were measured first when the prolapse was reduced and patient asked not to strain. Aa and Ap were marked using marker pen. Then patient was asked to strain maximally $C$ point (Figure A2), Aa, Ba, Ap, Bp points (Figure A3, Figure A4) were measured and last D point was measured. Grading of prolapse was decided by the distal edge of prolapse.

After completion of vaginal hysterectomy with site specific repair, post-operative POP Q scoring was done by surgeon in dorsal lithotomy position. Anatomical optimization was assessed on basis of comparison of pre-and postop scores. Same surgeon did the preop scoring, vaginal hystererctomy, post op POP Q scoring. The values were filled in the following tic tac toe grid design for each patient (Table A1, Table A2).

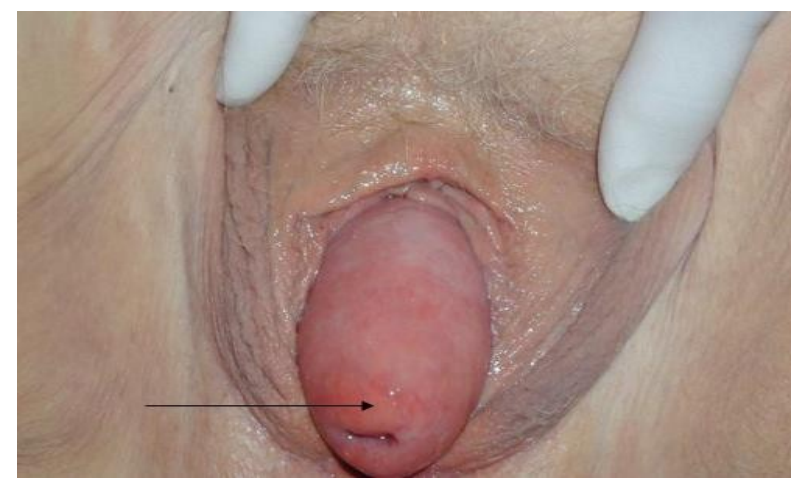

Figure A2. Point C; cervix.

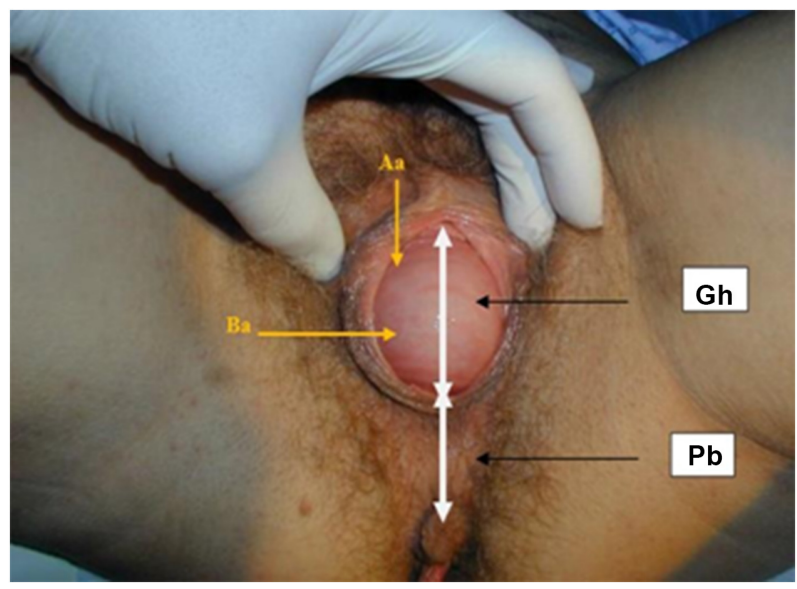

Figure A3. Position of points Aa, Ba genital hiatus and perineal body. 


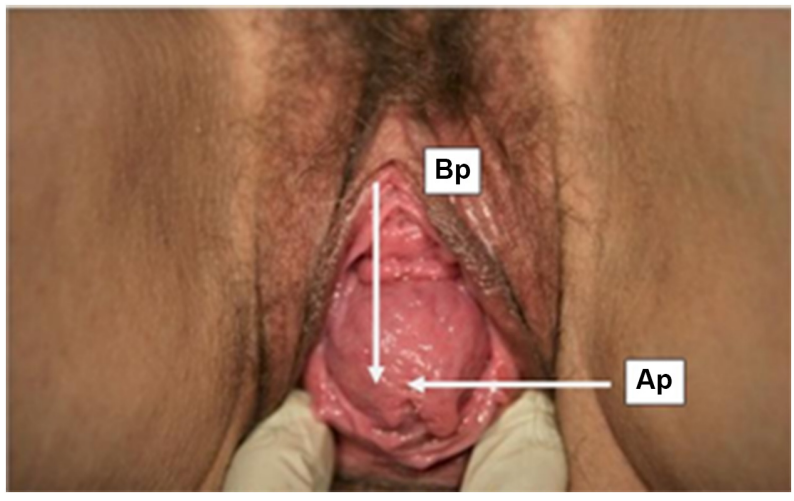

Figure A4. Position of points Ap and Bp.

Table A1. Tic tac toe grid.

\begin{tabular}{ccc}
\hline Aa Anterior vaginal wall & Ba Anterior vaginal wall & C Cervix or cervical cuff \\
\hline Gh: Genital hiatus & Pb: Perineal body & Tvl: Total vaginal length \\
Ba: Posterior vaginal wall & Bp: Posterior vaginal wall & D: Posterior fornix \\
\hline
\end{tabular}

Table A2. Staging of prolapse.

\begin{tabular}{l} 
No Prolpase. Points Aa, Ba, Ap, Bp are all at $-3 \mathrm{~cm}$. \\
\hline Stage I $\begin{array}{l}\text { The most distal portion of the prolapse is more than } 1 \mathrm{~cm} \text { above the level of hymen } \\
\text { Quantification value is less than }-1 \mathrm{~cm} .\end{array}$ \\
Stage II $\begin{array}{l}\text { The most distal portion of the prolapse is } 1 \mathrm{~cm} \text { or less proximal or distal to the hymen } \\
\text { Quantification value is } \geq-1 \mathrm{~cm} \text { but } \leq+1 \mathrm{~cm}\end{array}$ \\
Stage III $\begin{array}{l}\text { The most distal portion of the prolapse protrudes more than } 1 \mathrm{~cm} \text { below the hymenal } \\
\text { plane. Quantification value is }>+1 \text { but }<+(\text { tvl }-2 \mathrm{~cm})\end{array}$ \\
Stage IV Complete eversion of vaginal walls. Quantification value $>(+\mathrm{tvl}-2 \mathrm{~cm})$
\end{tabular}




\section{Appendix 2}

\section{Pelvic Organ Prolapse/Urinary Incontinence Sexual Function Questionnaire (PISQ-12)}

Instructions: Following are a list of questions about you and your partner's sex life. All information is strictly confidential. Your confidential answers will be used only to help doctors understand what is important to patients about their sex lives. Please check the box that best answers the question for you. While answering the questions, consider your sexuality over the past six months. Thank you for your help.

1. How frequently do you feel sexual desire? This feeling may include wanting to have sex, planning to have sex, feeling frustrated due to lack of sex, etc.

$$
\square \text { Always } \square \text { Usually } \square \text { Sometimes } \square \text { Seldom } \square \text { Never }
$$

2. Do you climax (have an orgasm) when having sexual intercourse with your partner?

$$
\square \text { Always } \square \text { Usually } \square \text { Sometimes } \square \text { Seldom } \square \text { Never }
$$

3. Do you feel sexually excited (turned on) when having sexual activity with your partner?

$$
\square \text { Always } \square \text { Usually } \square \text { Sometimes } \square \text { Seldom } \square \text { Never }
$$

4. How satisfied are you with the variety of sexual activities in you current sex life?

$$
\square \text { Always } \square \text { Usually } \square \text { Sometimes } \square \text { Seldom } \square \text { Never }
$$

5. Do you feel pain during sexual intercourse?

$$
\square \text { Always } \square \text { Usually } \square \text { Sometimes } \square \text { Seldom } \square \text { Never }
$$

6. Are you incontinent of urine (leak urine) with sexual activity?

$$
\square \text { Always } \square \text { Usually } \square \text { Sometimes } \square \text { Seldom } \square \text { Never }
$$

7. Does fear of incontinence (either stool or urine) restrict your sexual activity?

$$
\square \text { Always } \square \text { Usually } \square \text { Sometimes } \square \text { Seldom } \square \text { Never }
$$

8. Do you avoid sexual intercourse because of bulging in the vagina (either the bladder, rectum or vagina falling out?)?

$$
\square \text { Always } \square \text { Usually } \square \text { Sometimes } \square \text { Seldom } \square \text { Never }
$$

9. When you have sex with your partner, do you have negative emotional reactions such as fear, disgust, shame or guilt?

$$
\square \text { Always } \quad \square \text { Usually } \quad \square \text { Sometimes } \quad \square \text { Seldom } \quad \square \text { Never }
$$

10. Does your partner have a problem with erections that affects your sexual activity?

$$
\square \text { Always } \square \text { Usually } \square \text { Sometimes } \square \text { Seldom } \square \text { Never }
$$

11. Does your partner have a problem with premature ejaculation that affects your sexual activity?

$$
\square \text { Always } \square \text { Usually } \square \text { Sometimes } \square \text { Seldom } \square \text { Never }
$$

12. Compared to orgasms you have had in the past, how intense are the orgasms you have had in the past six months? $\square$ Much less intense $\square$ Less intense $\square$ Same intensity $\square$ More intense $\square$ Much more intense

Scoring:

Scores are calculated by totaling the scores for each question with $0=$ never, $4=$ always. Reverse scoring is used for items $1,2,3$ and 4 . The short form questionnaire can be used with up to two missing responses. To handle missing values the sum is calculated by multiplying the number of items by the mean of the answered items. If there are more than two missing responses, the short form no longer accurately predicts long form scores. Short form scores can only be reported as total or on an item basis. Although the short form reflects the content of the three factors in the long form, it is not possible to analyze data at the factor level. To compare long and short form scores multiply the short form score by $2.58(12 / 31)$ 